\title{
Comparison of Cloud Type Classification with Split Window Algorithm Based on Different Infrared Band Combinations of Himawari-8 Satellite
}

\author{
Babag Purbantoro',2, Jamrud Aminuddin',3, Naohiro Manago', Koichi Toyoshima1, \\ Nofel Lagrosas ${ }^{1}$, Josaphat Tetuko Sri Sumantyo', Hiroaki Kuze ${ }^{1}$ \\ ${ }^{1}$ Center for Environmental Remote Sensing, Chiba University, Chiba, Japan \\ ${ }^{2}$ Remote Sensing Technology and Data Center, Indonesian Institute of Aeronautics and Space (LAPAN), Jakarta, Indonesia \\ ${ }^{3}$ Department of Physics, Faculty of Mathematics and Natural Science, Universitas Jenderal Soedirman, Purwokerto, Indonesia \\ Email: babag.purbantoro@lapan.go.id,babag@chiba-u.jp
}

How to cite this paper: Purbantoro, B., Aminuddin, J., Manago, N., Toyoshima, K., Lagrosas, N., Sumantyo, J.T.S. and Kuze, H. (2018) Comparison of Cloud Type Classification with Split Window Algorithm Based on Different Infrared Band Combinations of Himawari-8 Satellite. Advances in Remote Sensing, 7, 218-234.

https://doi.org/10.4236/ars.2018.73015

Received: June 5, 2018

Accepted: September 18, 2018

Published: September 21, 2018

Copyright $\odot 2018$ by authors and Scientific Research Publishing Inc. This work is licensed under the Creative Commons Attribution International License (CC BY 4.0).

http://creativecommons.org/licenses/by/4.0/

cC) (7) Open Access

\begin{abstract}
Cloud detection and classification form a basis in weather analysis. Split window algorithm (SWA) is one of the simple and matured algorithms used to detect and classify water and ice clouds in the atmosphere using satellite data. The recent availability of Himawari- 8 data has considerably strengthened the possibility of better cloud classification owing to its enhanced multi-band configuration as well as high temporal resolution. In SWA, cloud classification is attained by considering the spatial distributions of the brightness temperature (BT) and brightness temperature difference (BTD) of thermal infrared bands. In this study, we compare unsupervised classification results of SWA using the band pair of band 13 and 15 (SWA13-15, 10 and $12 \mu \mathrm{m}$ bands), versus that of band 15 and 16 (SWA15-16, 12 and $13 \mu \mathrm{m}$ bands) over the Japan area. Different threshold values of BT and BTD are chosen in winter and summer seasons to categorize cloud regions into nine different types. The accuracy of classification is verified by using the cloud-top height information derived from the data of Cloud-Aerosol Lidar and Infrared Pathfinder Satellite Observations (CALIPSO). For this purpose, six different paths of the space-borne lidar are selected in both summer and winter seasons, on the condition that the time span of overpass falls within the time ranges between 01:00 and 05:00 UTC, which corresponds to the local time around noon. The result of verification indicates that the classification based on SWA13-15 can detect more cloud types as compared with that based on SWA15-16 in both summer and winter seasons, though the latter combination is useful for deli-
\end{abstract}


neating cumulonimbus underneath dense cirrus regions.

\section{Keywords}

Cloud Type Detection, Himawari-8, Split Window Algorithm, Brightness Temperature

\section{Introduction}

Precise classification of cloud types in satellite images is indispensable for the better understanding of cloud formation and development processes. While low Earth orbit satellites provide cloud images only once or twice a day, much more frequent images are available from meteorological satellites in the geostationary orbit. Himawari-8 satellite, launched on October 7, 2014 and operated by the Japan Meteorological Agency (JMA), started the official data dissemination from July 7, 2015. One of the advantages of Himawari-8 satellite data is the very high frequency of data acquisition $-10 \mathrm{~min}$ for the full disk and $2.5 \mathrm{~min}$ for the area around Japan. Himawari-8 is equipped with a sensor called Advanced Himawari Imager (AHI), which has a total of 16 bands in the visible (VIS, 3 bands), near-infrared (NIR, 3 bands) and infrared (IR, 10 bands) portion of the electromagnetic spectrum [1]. As compared with the former meteorological satellite of JMA (MTSAT, Himawari-7) that had a single, panchromatic channel in the visible part, a true-color image can be formed by assigning blue, green, and red to band 1, 2 and 3 of AHI, respectively.

Detection of clouds and estimation of cloud physical parameters are important topics in the data analysis of meteorological satellites. Previous works have revealed, for instance, that thick cloud can be detected using $0.64 \mu \mathrm{m}$ channel reflectance (R0.64) using a certain threshold [2], though this technique is not valid over the bright surface [3]. Cloud parameters, on the other hand, can be estimated by means of the information provided from both NIR and IR bands. For example, optical depth and ice particle size of cirrus clouds were retrieved using 1.38 and $1.88 \mu \mathrm{m}$ channels [4], which correspond to band 5 (centered at 1.61 $\mu \mathrm{m}$ ) of Himawari-8. During the daytime, the reflectance of visible and NIR band are more informative than during the night time. According to Bessho et al. (2016) [1], band 7, a mid-IR band centered at $3.88 \mu \mathrm{m}$, has the capability of detecting low-level cloud and fog. During the daytime, low-level water clouds are effectively detected by using the brightness temperature difference (BTD) between the 11 and $3.7 \mu \mathrm{m}$ bands (BTD11-3.7) [2]. Bessho et al. (2016) [1] indicated that water vapor bands located at $6.2,6.9$ and $7.3 \mu \mathrm{m}$ are useful for cloud phase detection. In relation to the BTD and cloud properties, the use of TIR bands were proposed for other meteorological satellites, such as the cloud top height estimation using MODIS [5] and Meteosat [6], cirrus and water vapor detection using Meteosat [7], cloud phase and cloud optical thickness using Meteosat [8], and rainfall detection [9]. Also, the movement of water vapor detected 
by means of 6.2 and $7.3 \mu \mathrm{m}$ bands (BTD 6.2-7.3) was used to study wind movement and convection [6]. Strabala et al. (1994) [10] reported cloud type detection using BTD values from three spectral bands at 8,11 , and $12 \mu \mathrm{m}$. In their work, cloud phase was determined by comparing BTD8-11 and BTD11-12, because of the observation that the scattering of water and ice clouds is different near $12 \mu \mathrm{m}$. Also, seven types of clouds were discriminated on the basis of the comparison between BT11.2 and BTplev11.2 of Himawari-8 IR band [11]: here "plev" denotes a constant pressure value between surface and tropopause. Shang et al. (2017) [12] modelled a formula using BT11.2, BTD11.2-3.9 and R0.64 to delineate cold cloud over inland water, liquid/ice cloud, and cloud over land, respectively.

Split window algorithm (SWA) has widely been used for the analysis and classification of satellite imagery. Recent researches used SWA for the estimation of land surface temperature [13] [14] [15] [16] [17] as well as the estimation of cirrus cloud top height [18]. In the region of cloud classification, SWA was first introduced by Inoue (1987) [19] by utilizing two-dimensional threshold values of BT and BTD. Subsequently, Inoue [19] used the 11 and $12 \mu \mathrm{m}$ channels of NOAA 7 to detect the cumulonimbus $(\mathrm{Cb})$, cumulus $(\mathrm{Cu})$, dense cirrus $(\mathrm{Dc})$ and cirrus $(\mathrm{Ci})$ clouds over the tropical ocean. It was found that distinguishing $\mathrm{Ci}$ cloud from the land area was difficult, especially in the night time, though the threshold value was not explicitly shown. Hamada et al. (2004) [20] tried to make cloud classification using GMS-5 VISSR by modifying Inoue's approach, and identified cloud types by using ground-based observation. The threshold values of BTD11-12 and the BT11 were determined to be 1.8 and $250 \mathrm{~K}$, respectively. Inoue continued his research in cloud classification using SWA over the eastern sub-tropical Pacific area [21]. They used 11 and $12 \mu \mathrm{m}$ bands of NOAA-9 data in combination with coincident and collocated Earth Radiation Budget Experiment (ERBE) S-8 data. As a result, generally three cloud types, namely, $\mathrm{Cb}, \mathrm{Cu}$, and $\mathrm{Ci}$, were classified using BT and BTD thresholds. Three types of $\mathrm{Ci}$ were found as inferred from the thickness and cloud-top temperature. Subsequently, Lutz et al. (2003) [5] reported cloud type classification by applying the SWA using 11 and $12 \mu \mathrm{m}$ bands in the Meteosat Second Generation (MSG) method. Although high-Cb, middle-Cb, low- $\mathrm{Cb}, \mathrm{Dc}$, thick cirrus, $\mathrm{Ci}$, and thin cirrus were detected separately, their approach could not distinguish between ice and water clouds. A brief overview of the previous SWA researches is shown in Table 1.

In order to validate the classification results based on Himawari-8 imagery, we utilize the observation data of a space-borne lidar, namely, the Cloud-Aerosol Lidar and Infrared Pathfinder Satellite Observation (CALIPSO) [22]. CALIPSO was launched in 2006 by NASA and CNES to the low-Earth orbit with the altitude of approximately $690 \mathrm{~km}$ above surface. A Mie-scattering lidar provides the vertical profiles of aerosols and clouds at the two wavelengths generated from a Nd:YAG laser (532 and $1064 \mathrm{~nm}$ ). Also, the information on water/ice cloud 
Table 1. Overview of SWA in previous researches.

\begin{tabular}{|c|c|c|c|c|c|c|}
\hline & \multirow{2}{*}{$\begin{array}{l}\text { Inoue, } \\
1987\end{array}$} & \multirow{2}{*}{$\begin{array}{l}\text { Inoue \& } \\
\text { Ackerman, } \\
2002\end{array}$} & \multirow{2}{*}{$\begin{array}{l}\text { Lutz \& Inoue, } \\
\qquad 2003\end{array}$} & \multirow{2}{*}{ Hamada, 2004} & \multicolumn{2}{|c|}{ This Research } \\
\hline & & & & & SWA13-15 & SWA15-16 \\
\hline $\mathrm{X}$-axis BT & $11 \mu \mathrm{m}$ & $11 \mu \mathrm{m}$ & $11 \mu \mathrm{m}$ & $11 \mu \mathrm{m}$ & $10.4 \mu \mathrm{m}$ & $12.4 \mu \mathrm{m}$ \\
\hline Threshold X-axis & - & $\begin{array}{c}-20^{\circ} \mathrm{C} \& \text { Clear } \\
\mathrm{BT}\end{array}$ & $400 \mathrm{~Pa}, 600 \mathrm{~Pa}$ & $250 \mathrm{~K}$ & $\begin{array}{l}\text { Winter: } 245 \& 253 \mathrm{~K} \\
\text { Summer: } 250 \& 258 \mathrm{~K}\end{array}$ & $\begin{array}{l}\text { Winter: } 248 \& 256 \mathrm{~K} \\
\text { Summer: } 253 \& 261 \mathrm{~K}\end{array}$ \\
\hline Y-axis BTD & $11-12 \mu \mathrm{m}$ & $11-12 \mu \mathrm{m}$ & $11-12 \mu \mathrm{m}$ & $11-12 \mu \mathrm{m}$ & $10.4-12.4 \mu \mathrm{m}$ & $12.4-13.3 \mu \mathrm{m}$ \\
\hline Threshold Y-axis & - & $\begin{array}{c}1{ }^{\circ} \mathrm{C} \& \\
\text { ClearBTD }\end{array}$ & $1 \& 2.5$ & $0.5 \& 2.5$ & $\begin{array}{l}\text { Winter: } 0.6 \& 3.2 \mathrm{~K} \\
\text { Summer: } 0.9 \& 4.5 \mathrm{~K}\end{array}$ & $\begin{array}{l}\text { Winter: } 1.0 \& 14 \mathrm{~K} \\
\text { Summer: } 0.8 \& 14 \mathrm{~K}\end{array}$ \\
\hline \#Cloud type & 4 & 3 & 8 & 4 & 9 & 9 \\
\hline Name of clouds & $\mathrm{Cb}, \mathrm{Cu}, \mathrm{Dc}, \mathrm{Ci}$ & $\mathrm{Cb}, \mathrm{Ci}, \mathrm{Cu}$ & $\begin{array}{c}\text { Hi-Cb, } \\
\text { Mid-Cb, } \\
\text { Lo-Cb, DCi, } \\
\text { Water } \\
\text { cloud/ice } \\
\text { cloud, Thick } \\
\text { Ci, Ci, Thin Ci }\end{array}$ & $\mathrm{Cb}, \mathrm{Dc}, \mathrm{Ci}, \mathrm{Cu}$ & $\begin{array}{l}\text { Hi-Cb, Mid-Cb, Cu, } \\
\text { DCi, ice cloud, water } \\
\text { cloud, Thick Ci, Ci, } \\
\text { Thin Ci }\end{array}$ & $\begin{array}{c}\text { Hi-Cb, Mid-Cb, Cu, } \\
\text { DCi, ice cloud, water } \\
\text { cloud, Thick Ci, Ci, } \\
\text { Thin Ci }\end{array}$ \\
\hline Main Data & NOAA7 & NOOA9 & MODIS & GMS-5 & Himawari-8 & Himawari-8 \\
\hline
\end{tabular}

Note: $\mathrm{Cb}=$ Cumulonimbus; $\mathrm{Cu}=$ Cumulus; $\mathrm{DCi}=$ Dense Cirrus; $\mathrm{Ci}=$ Cirrus; $\mathrm{Hi}=$ High; Mid = Middle; Lo = Low.

phase is available using the depolarization ratio of the lidar backscatter signal [22].

The remaining part of this paper is organized as follows. In Section 2, the methodology of present work will be described, with the pertinent information on data processing and validation. In Section 3, the results are shown for particular cases chosen with the criteria of concurrent observation with the Himawari-8 satellite and CALIPSO, and comparison is made between the two pairs of IR bands for implementing SWA. Finally, conclusions will be given in Section 4 .

\section{Method}

\subsection{Band Selection of Himawari-8}

Himawari-8 data are obtained from the archive of the Center for Environmental Remote Sensing (CEReS), Chiba University (http://www.cr.chiba-u.jp/japanese/database.html), which provides the original and gridded data to the science community under the contract with JMA. In terms of energy transfer process between the surface and atmosphere, the atmospheric window wavelength is ranged between $8-12$ $\mu \mathrm{m}$, which is largely or partially transparent to most of atmospheric gases [23]. As seen from Table 1, most of the previous researches employed the combination of 10 and $11 \mu \mathrm{m}$ bands for implementing SWA.

Figure 1 shows an example of BT histograms of a Himawari-8 image (observed on April 1, 2016 around Japan area) for ten IR bands covering the wavelength range of $3.9-13.3 \mu \mathrm{m}$. Similar comparison of histograms has also been made for images captured in winter and summer seasons. Based on the shapes of 


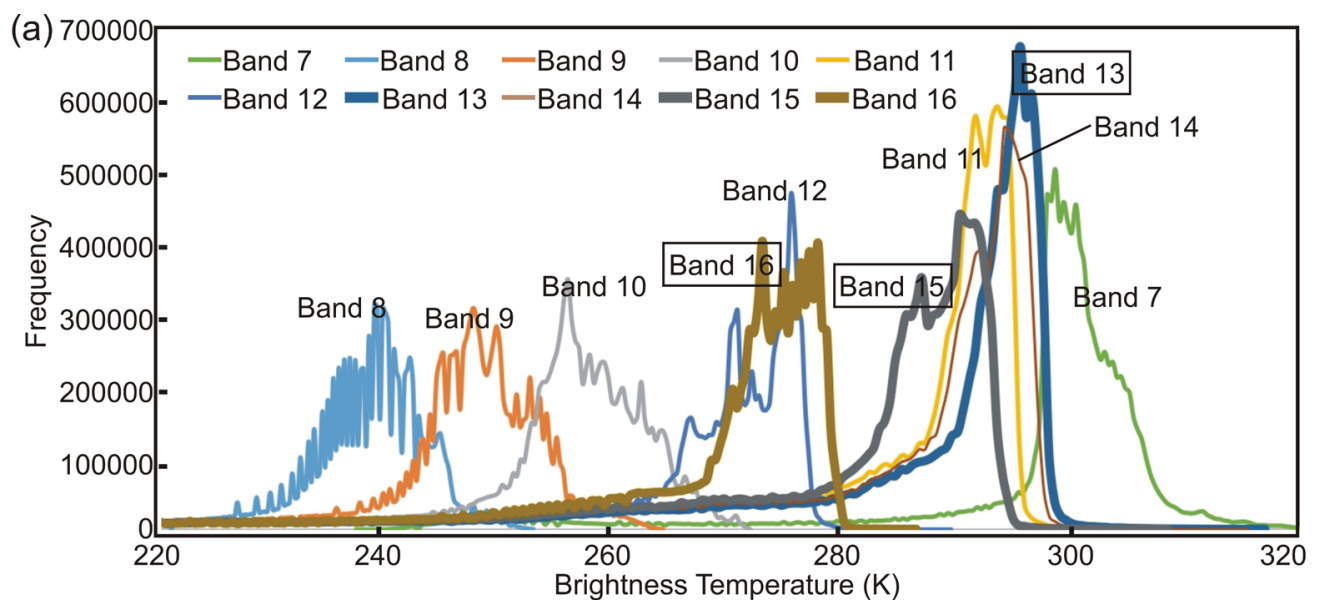

\begin{tabular}{cc} 
(b) $\begin{array}{c}\text { Band } \\
\#\end{array}$ & $\begin{array}{c}\text { Center } \\
\text { Wavelength } \\
(\mu \mathrm{m})\end{array}$ \\
\hline 7 & 3.9 \\
\hline 8 & 6.2 \\
\hline 9 & 6.9 \\
\hline 10 & 7.3 \\
\hline 11 & 8.6 \\
\hline 12 & 9.6 \\
\hline 13 & 10.4 \\
\hline 14 & 11.2 \\
\hline 15 & 12.4 \\
\hline 16 & 13.3 \\
\hline
\end{tabular}

Figure 1. (a) BT Histogram of Himawari-8 IR bands. The original image data were recorded at 02:00 UTC (11:00 Japan Standard Time) on April 1, 2016. Band 13, 15 and 16 in the atmospheric window range are used in this research for testing the usefulness of SWA; (b) The IR bands of Himawari-8 with their center wavelengths.

the histograms of atmospheric window bands (band 13,14,15 and 16) seen in Figure 1, here we select the band pairs of $13-15$ and $15-16$ for implementing cloud classification. Among the four bands, band 13 exhibits the narrowest histogram. The wavelength difference of the combination of band 13 - 14 or band $14-15$ is too small, which may result in the loss of accuracy in the calculation of BTD. In the present work, we compare the classification accuracy for the two cases of SWA13-15 (inside the atmospheric window range) and SWA15-16 (slightly outside the atmospheric window range). The area of interest is the Japan area, at which the Himawari-8 imagery is available every $2.5 \mathrm{~min}$. The Himawari- 8 bands utilized in this research are band 1 (centered at $0.47 \mu \mathrm{m}), 4$ $(0.86 \mu \mathrm{m}) 13(10.4 \mu \mathrm{m}), 15(12.4 \mu \mathrm{m})$ and $16(13.3 \mu \mathrm{m})$.

\subsection{CALIPSO Data}

CALIPSO data are obtained from the Atmospheric Science Data Center of NASA Langley Research Center. The BT information from satellite observation is pertinent to the temperature of cloud top, and CALIPSO lidar data are useful for validating the cloud-top height. Concurrent data sets of Himawari-8 and CALIPSO have been selected during winter and summer seasons in 2016. Among the six cases summarized in Table 2, January 1, January 6, and March 19 represent the winter season, while June 1, July 2, August 29 the summer season. These dates were selected considering the availability of the data of CALIPSO that passes over the Chiba area in the time range of 01:00 - 05:00 UTC or 10:00 14:00 Japan Standard Time (JST). Attenuated backscattering, depolarization ratio, and ice/water phase parameter of CALIPSO data are used in this research. The Himawari- 8 data that coincide with the overpass time are downloaded in the geo-corrected format cropped in the Japan area $\left(22.02^{\circ} \mathrm{N}-47.74^{\circ} \mathrm{N}\right.$ and $\left.120.11^{\circ} \mathrm{E}-156.99^{\circ} \mathrm{E}\right)$. In addition to the high frequency observation, ten minutes interval cloud image movie (hereafter image movie) is available by using band 4 
Table 2. Date and time of each dataset.

\begin{tabular}{ccccl}
\hline No & Date & CALIPSO & Himawari-8 & Season \\
\hline 1 & January 1, 2016 & $03.35-03.47$ UTC & 03.40 UTC & Winter \\
2 & January 6, 2016 & $03.53-04.05$ UTC & 04.00 UTC & Winter \\
3 & March 19, 2016 & $03.45-04.07$ UTC & 03.40 UTC & Winter \\
4 & June 1, 2016 & $04.07-04.30$ UTC & 04.20 UTC & Summer \\
5 & July 2, 2016 & $03.41-03.54$ UTC & 03.40 UTC & Summer \\
6 & August 29, 2016 & $04.14-04.28$ UTC & 04.20 UTC & Summer \\
\hline
\end{tabular}

for the time range of around 00:00 - 06:00 UTC (09:00 - 15:00 JST). This tool helps to facilitate the visual interpretation process during the cloud interpretation and threshold adjustment.

\subsection{Albedo Calculation}

Band 1 data of Himawari- 8 centered at $0.47 \mu \mathrm{m}$ are used for the simple detection of cloud areas characterized with high reflectance (albedo) values. In this band, most of bright objects are considered to be cloud, though snow cover in land areas exhibits similarly high reflectance especially in the middle latitude zone. The calculation of albedo, $A$, is carried out by using the following formula:

$$
I=\text { Gain } * \text { Count }+ \text { Constant }, A=c^{\prime} I .
$$

Here $I$ is the radiance, which is calculated for each pixel from the digital count of Himawari- 8 band 1 . Then, the albedo value, $A$, is calculated by multiplying the radiance with the transformation coefficient, $c^{\prime}$ [24]. In Equation (1), the values of Gain, Constant and $c^{\prime}$ are derived from the header information file of Himawari-8. The resulting value of $A$ is between 0 and 1 , and the present examination of a number of pixels has led to a threshold value of $A=0.2$, i.e., if $A>0.2$, it is considered as a cloud pixel for daytime images.

\subsection{BT and BTD Calculation}

The BT value is derived for band 13 (hereafter BT13), band 15 (BT15) and 16 (BT16) of Himawari-8 using the principle of Planck's radiation law. The BT values of these three bands are employed also for calculating BTD13-15 and BTD15-16. For an IR band with a center wavelength of $\lambda$, the value of BT can be calculated as [24]:

$$
B T=c_{0}+c_{1} T_{\mathrm{e}}+c_{2} T_{\mathrm{e}}^{2}
$$

and

$$
T_{\mathrm{e}}=\frac{h c}{k \lambda}\left[\ln \left(\frac{2 h c^{2}}{\lambda^{5} I}+1\right)\right]^{-1} .
$$

Here, $c_{0}, c_{1}$, and $c_{2}$ are constants that can be obtained from the header information file of Himawari- 8 for each band. The radiance, $I$, is calculated for each 
pixel from the digital count of each band using Equation (1); $h$ is the Planck constant, $k$ is the Boltzmann constant, and $c$ is the speed of light. The BTD13-15 is calculated as the difference between BT13 and BT15 while BTD15-16 between BT15 and BT16.

\subsection{SWA Implementation}

Here we examine two schemes of SWA, namely SWA13-15 that is based on TB13 ( $\mathrm{x}$ axis) and BTD13-15 (y axis) and SWA15-16 based on TB15 and BTD15-16. Figure 2 shows the nine types of cloud classes resulting from the present unsupervised classification. In this matrix, lower values of BT correspond to higher clouds, and smaller values of BTD correspond to thicker clouds. Cirrus (Type \#8) and thin cirrus (type \#9) are exceptional in that they exhibit higher values of BT, which generally suggest middle or low-level clouds. This is due to the influence of the surface below the cirrus or thin cirrus clouds that have semi-transparent features. The threshold values (BT-1, BT-2, BTD-1, and BTD-2) are tabulated in Table 3 for the two SWA schemes for both winter and summer cases: see Section 3 below for the determination procedure of these threshold values.

\subsection{Verification of Cloud Phase and Altitude}

The depolarization ratio $(\rho)$ provided in the CALIPSO data is employed here for

\begin{tabular}{|c|c|c|c|c|}
\hline & High-Cloud & Middle-Cloud & Low-Cloud & \\
\hline & $\begin{array}{l}\text { Type \#7 } \\
\text { Thick Cirrus }\end{array}$ & $\begin{array}{l}\text { Type \#8 } \\
\text { Cirrus }\end{array}$ & $\begin{array}{l}\text { Type \#9 } \\
\text { Thin Cirrus }\end{array}$ & Thin-Cloud \\
\hline & $\begin{array}{l}\text { Type \#4 } \\
\text { Dense Cirrus }\end{array}$ & $\begin{array}{l}\text { Type \#5 } \\
\text { Ice Cloud }\end{array}$ & $\begin{array}{l}\text { Type \#6 } \\
\text { Water Cloud/ } \\
\text { Stratocumulus/ } \\
\text { Stratus }\end{array}$ & $\begin{array}{l}\text { Thick and } \\
\text { Dense-Cloud }\end{array}$ \\
\hline & $\begin{array}{l}\text { Type \#1 } \\
\text { High } \\
\text { Cumulonimbus }\end{array}$ & $\begin{array}{l}\text { Type \#2 } \\
\text { Middle } \\
\text { Cumulonimbus }\end{array}$ & $\begin{array}{l}\text { Type \#3 } \\
\text { Cumulus }\end{array}$ & $\begin{array}{l}\text { Very Thick/ } \\
\text { Developed } \\
\text { Cloud }\end{array}$ \\
\hline
\end{tabular}

Figure 2. Matrix employed for cloud classification based on SWA. The threshold values of BT-1, BT-2, BTD-1, and BTD-2 are summarised separately in Table 3 . The colors in this matrix will also be used for indicating different cloud types in Figure 4 and Figure 5 below.

Table 3. Summary of threshold temperatures (K) determined for both winter and summer seasons from the present analysis of cloud images around Japan.

\begin{tabular}{ccccc}
\hline & \multicolumn{2}{c}{ Winter Season } & \multicolumn{2}{c}{ Summer Season } \\
\cline { 2 - 5 } & SWA13-15 & SWA15-16 & SWA13-15 & SWA15-16 \\
\hline BT-1 & 245 & 248 & 250 & 253 \\
BT-2 & 253 & 256 & 258 & 261 \\
BTD-1 & 0.6 & 1.0 & 0.9 & 0.8 \\
BTD-2 & 3.2 & 14 & 4.5 & 14 \\
\hline
\end{tabular}


checking the cloud phase. The water and ice cloud typically have $\rho$ less than 0.1 and more than 0.3 , respectively. The value of $\rho$ between 0.1 and 0.3 indicates mixed-phase cloud [25]. Generally high-level clouds tend to exhibit large $\rho$ values, and low-level cloud small $\rho$ values.

Clouds can be roughly classified into three levels on the basis of their altitudes, namely, low-level $(<3 \mathrm{~km})$, middle-level $(3-6 \mathrm{~km})$, and high-level cloud $(>6 \mathrm{~km})$. Because of the average lapse rate of troposphere $(\sim 6.5 \mathrm{~K} / \mathrm{km})$, the difference in altitude leads to the difference in BT. Thus, the cloud top height, $h$, can be estimated from the value of BT observed for the cloud pixel as [26]

$$
h=\frac{1}{\delta}\left(T_{\mathrm{s}}-T_{\mathrm{CT}}\right) .
$$

Here $\delta=6.5 \mathrm{~K} / \mathrm{km}$ is the standard value of the vertical lapse rate, $T_{\mathrm{S}}$ is the surface temperature, and $T_{\mathrm{CT}}$ is the cloud top temperature. In the present work, we apply Equation (4) to check the cloud top height over the Chiba area by assuming that $T_{\mathrm{CT}}$ is equal to BT13 with $T_{\mathrm{S}}$ value observed at Chiba University.

\section{Results and Discussion}

Six datasets of Himawari-8 imagery listed in Table 2 are processed and verified during the test. Figure 3(a) shows the albedo distribution generated from the band 1 image observed at 03:40 UTC (12:40 JST) on July 2, 2017, while Figure 3 (b) the result of cloud extraction using the threshold value of $A>0.2$. As compared with other visible bands, band 1 centered at $0.47 \mu \mathrm{m}$ gives the best discrimination of cloud and non-cloud (surface) areas. Figures 3(c)-(h) show albedo images for each of the dataset listed in Table 2. In Figure 3(c), streak patterns due to the formation of cumulus clouds are seen over the Japan Sea area. These clouds often develop into cumulonimbus due to the orographic effect, resulting in heavy snowfall in the northern part of central Japan. Both in panels (d) and (e), frontal clouds are seen in the southern part of the Honshu Island. In panels ( $\mathrm{f}$ ) and (g), clouds due to the Baiu front are seen in addition to the cloud system related to a low pressure in the northern part. A developed cloud system in association with a typhoon is seen in panel (h). In addition, it is noted that in winter season such as in panel (c), some land areas in northern Japan are covered with snow, which tend to be misclassified as cloud areas. The examination of image movie, as mentioned above, is useful for discriminating clouds from snow-covered surface areas.

The threshold values of BT and BTD listed in Table 3 have been determined through the examination of a number of images (not limited to the six datasets in Table 2) with the help of the image movie. The visual observation of the movie greatly facilitated the assignment of cloud types based on their movement and appearance. In the following, some explanations are given on the recognition of cloud characteristics.

Cumulonimbus clouds ( $\mathrm{Cb}$, type \#1) always exhibit high brightness in the albedo image, indicating the very thick nature as a result of vertical development. 

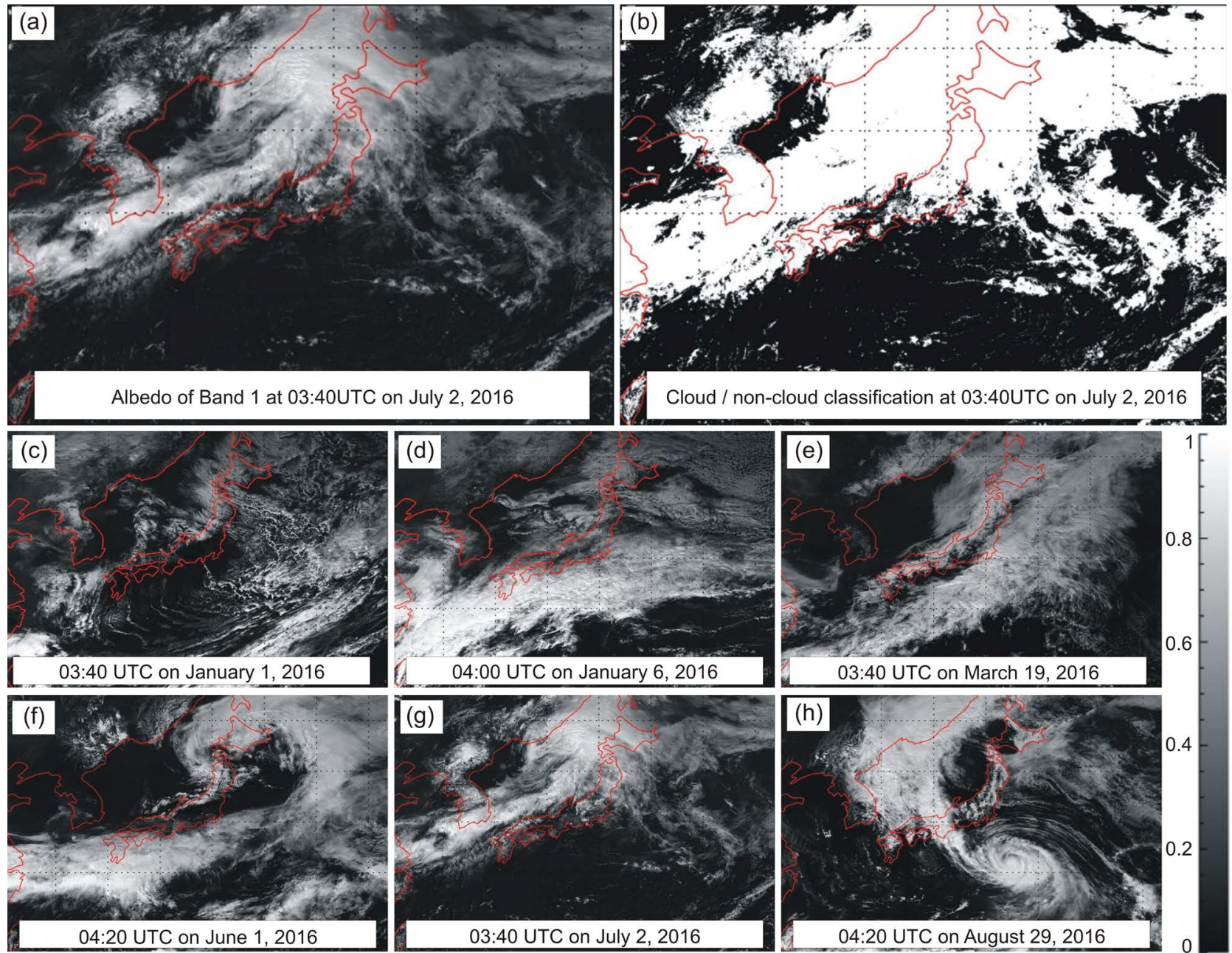

Figure 3. (a) Albedo distribution for the band 1 data observed at 03:40 UTC on July 2, 2017 (dataset \#5), in comparison with (b) the resulting discrimination of cloud (white) and non-cloud (black) areas using the threshold value of 0.2. (c)-(h) Albedo distribution derived from Himawari-8 band 1 data for each observation day listed in Table 2.

Sometimes they are overlapped with a large area of dense and thick cirrus clouds (Dc, type \#4) that move together [27], as actually seen in the case of Figure 3(e). Also, they are detected around a typhoon, as seen in Figure 3(h). Sometimes it appears as middle-cloud without anvil as middle cumulonimbus ( $\mathrm{Mi}-\mathrm{Cb}$, type \#2) and ice cloud (type \#5). In the pre-development stage of cumulonimbus, cumulus clouds (type \#3) are detected as low-level clouds.

Low-level cloud is mostly dominated by water cloud (type \#6) with a very large spatial coverage and non-uniform appearance. Cumulus clouds $(\mathrm{Cu}$, type \#3) form as small clusters. Since they are low-level clouds, their movement is often affected by the existence of high mountains. Stratocumulus (Sc) and nimbostratus (Ns) exhibit similar appearance as cumulus, but with larger spatial coverage. Nimbostratus (Ns) is rain cloud with substantial thickness. In some cases, we found difficulty in delineating low-level clouds only from their appearance in image movie because of their similarity and lack of spatial resolution.

It is found that the movement of cirrus cloud (Ci, type \#8) is mostly on top of 
other cloud types. Cirrus clouds are characterized with semi-transparent and smooth texture. Thin cirrus (type \#9) and cirrus are high clouds with cloud top height of more than $6 \mathrm{~km}$.

Type \#4 is dense cirrus (Dc): they appear as high clouds, sometimes forming an anvil during the development process of cumulonimbus (type \#1). The appearance is always very dense with wide spatial coverage. Sometimes cirrus clouds exhibit non-uniform shapes and located in the surrounding of the dense cirrus as ice clouds (type \#5).

The determination of threshold values in BT and BTD is carried out by constructing scatter diagrams. Figure 4 shows examples of scatter diagram for dataset \#1 (Figure 4(a) and Figure 4(b)) and dataset \#5 (Figure 4(c) and Figure 4(d)) analyzed by means of SWA13-15 (Figure 4(a) and Figure 4(c)) and SWA15-16 (Figure 4(b) and Figure 4(d)). In the case of dataset \#5, the mean value of BTD13-15 is $4.32 \mathrm{~K}$, which is substantially smaller than that of BTD15-16 (11.68 $\mathrm{K})$. The maximum values, on the other hand, are similar, 27.86 K for BTD13-15 and $27.91 \mathrm{~K}$ for BTD15-16.

Wider spread is seen for the scatter plot of SWA13-15 than that for SWA15-16. From the scatter plot of SWA15-16 (Figure 4(d)), it is understood that cumulus clouds with high BT and low BTD cannot be detected: this is in clear contrast with SWA13-15, where cumulus is successfully detected. The detection of thin cirrus (with high BT and BTD), on the other hand, can be facilitated using the scheme of SWA15-16 (Figure 4(d)). The similar trend of scatter plot diagram is found in other datasets, e.g. dataset \#1. The shape of the BTD13-15 tends to spread more widely than BTD15-16. When compared with the winter diagram (Figure 4(a) and Figure 4(b)), summer scatter plots (Figure 4(c) and Figure 4(d)) tends to spread more widely on both BT (x axis) and BTD (y axis).

The results of final cloud classification, made by combining the results of cloud area extraction (Figure $3(\mathrm{~b})$ ) and split window implementation, are shown in Figure 5 for the two cases of (A) SWA13-15 and (B) SWA15-16. In Figure 5(A) based on SWA13-15, the most noticeable cloud type is dense cirrus
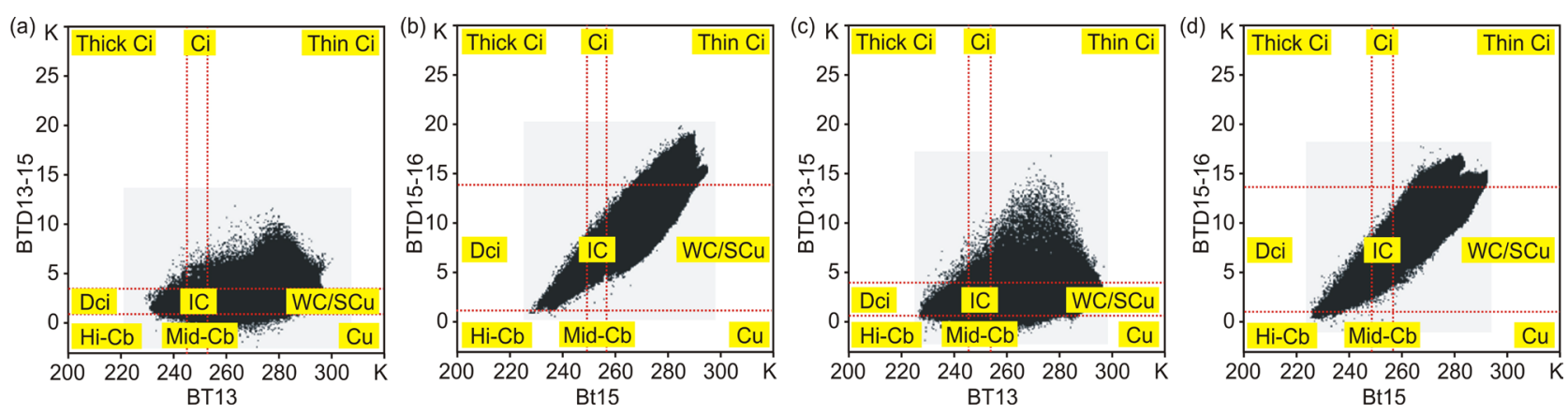

Figure 4. Scatter diagrams of Himawari-8 data showing the relationship between BT and BTD at ((a) and (b)) 03:40 UTC on January 1, 2016 and ((c) and (d)) 03:40 UTC on July 2, 2016. (a) and (c) are the results for SWA13-15, while (b) and (d) for SWA15-16. Ci: cirrus, DCi: dense cirrus, IC: ice cloud, WC: Water cloud, SCu: stratocumulus, Hi-Cb: high cumulonimbus, Mid-Cb: middle cumulonimbus, and $\mathrm{Cu}$ : cumulus. 

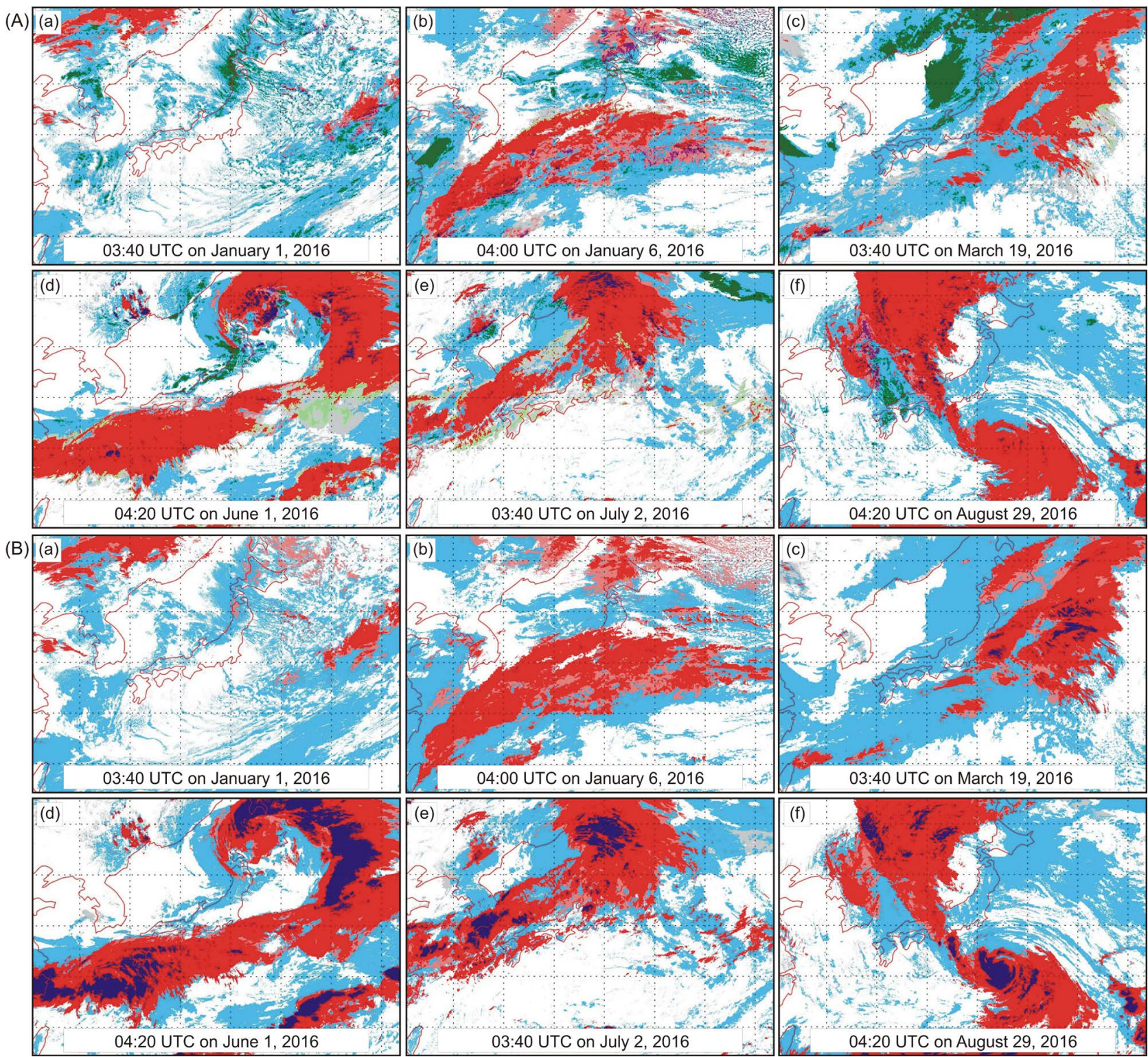

Figure 5. Results of cloud classification for the different band combinations of (A) SWA13-15 and (B) SWA15-16. Colors of different cloud types are the same as those in Figure 2; white color indicates areas with no cloud coverage.

(type \#4 in red color), followed by water cloud that includes stratocumulus and stratus (type \#6, light blue). Also, cumulus clouds (type \#3, dark green) are found in most of the panels, especially in the northern part of panel (c). Ice clouds (type \#5, pink) are found in the northern part of panel (b), in addition to the rim of dense cirrus. In panel (d), a region of thick cirrus (type \#7, light green) appears over that of thin cirrus clouds (type \#9, grey).

In Figure 5(B) based on SWA15-16, on the other hand, the distribution of dense cirrus (type \#4, red) is more or less similar to that in Figure 5(A), though central portions are sometimes replaced with cumulonimbus (type \#1, blue), especially in images in summer season, i.e., panels (d)-(f). Since these cases represent rainfall events in relation to the frontal system ((d) and (e)) or a ty- 
phoon (f), the result in Figure 5(B) is more reasonable than that in Figure 5(A). The spread of water cloud (type \#6, light blue) is also similar to the case in Figure 5(A), but most of cumulus clouds (type \#3, green) that have been seen in Figure 5(A) are not found in Figure 5(B). Similarly, thick cirrus regions (type \#7, light green) are not seen in the case of Figure 5(B).

All the results of cloud type detection are summarized in Table 4. From this table, it is apparent that generally SWA13-15 exhibits more sensitivity for different cloud types. SWA13-15 can detect by $50 \%, 43 \%, 29 \%, 29 \%, 38 \%$, and $17 \%$ more cloud types than SWA15-16 for dataset \#1 through \#6, respectively. However, SWA15-16 gives more appropriate discrimination between dense cirrus and cumulonimbus. Although SWA15-16 exhibits rather limited capability in discriminating different cloud types, the results are not contradictory to the cloud types inferred from SWA13-15. For example, cumulus clouds (type \#3, dark green) that have been detected on the northern part of panels (a), (b) and (c) using SWA13-15 are detected as water clouds (type \#6, light blue) using SWA15-16. This is not an incompatible situation, since the cumulus type is part of water cloud. Similarly, thick cirrus clouds (type \#7, light green) detected on SWA13-15 in panels (d) and (e) are detected as dense cirrus (type \#4, red color) using SWA15-16, but both types belong to the cirrus cloud family.

In both Figure 5(A) and Figure 5(B), snow-covered land areas have been

Table 4. Results of cloud detection for the two SWAs.

\begin{tabular}{|c|c|c|c|c|c|c|c|c|c|c|c|c|c|}
\hline \multirow{3}{*}{$\begin{array}{l}\text { Тyp } \\
\text { e \# }\end{array}$} & \multirow{3}{*}{ Name of Cloud } & \multicolumn{2}{|c|}{$\begin{array}{l}\text { Dataset \#1 } \\
\text { Jan 01, } 2016\end{array}$} & \multicolumn{2}{|c|}{$\begin{array}{c}\text { Dataset \#2 } \\
\text { Jan } 06,2016\end{array}$} & \multicolumn{2}{|c|}{$\begin{array}{c}\text { Dataset \#3 } \\
\text { April 19, } 2016\end{array}$} & \multicolumn{2}{|c|}{$\begin{array}{c}\text { Dataset \#4 } \\
\text { June } 01,2016\end{array}$} & \multicolumn{2}{|c|}{$\begin{array}{l}\text { Dataset \#5 } \\
\text { July } 02,2016\end{array}$} & \multicolumn{2}{|c|}{$\begin{array}{c}\text { Dataset \#6 } \\
\text { Aug 29, } 2016\end{array}$} \\
\hline & & SWA & SWA & SWA & SWA & SWA & SWA & SWA & SWA & SWA & SWA & SWA & SWA \\
\hline & & $13-15$ & $15-16$ & $13-15$ & $15-16$ & $13-15$ & $15-16$ & $13-15$ & $15-16$ & $13-15$ & $15-16$ & $13-15$ & $15-16$ \\
\hline 1 & High Cumulonimbus & ND & ND & ND & ND & $\mathrm{D}$ & $\mathrm{D}$ & ND & ND & ND & ND & $\mathrm{D}$ & $\mathrm{D}$ \\
\hline 2 & Mid Cumulonimbus & ND & ND & $\mathrm{D}$ & ND & ND & ND & ND & ND & $\mathrm{D}$ & ND & ND & ND \\
\hline 3 & Cumulus/Nimbostratus & $\mathrm{D}$ & ND & $\mathrm{D}$ & ND & $\mathrm{D}$ & ND & $\mathrm{D}$ & ND & $\mathrm{D}$ & ND & $\mathrm{D}$ & ND \\
\hline 4 & Dense Cirrus & $\mathrm{D}$ & $\mathrm{D}$ & $\mathrm{D}$ & $\mathrm{D}$ & $\mathrm{D}$ & $\mathrm{D}$ & $\mathrm{D}$ & $\mathrm{D}$ & $\mathrm{D}$ & $\mathrm{D}$ & $\mathrm{D}$ & $\mathrm{D}$ \\
\hline 5 & Ice Cloud & $\mathrm{D}$ & $\mathrm{D}$ & $\mathrm{D}$ & $\mathrm{D}$ & $\mathrm{D}$ & $\mathrm{D}$ & $\mathrm{D}$ & $\mathrm{D}$ & $\mathrm{D}$ & $\mathrm{D}$ & $\mathrm{D}$ & $\mathrm{D}$ \\
\hline 6 & $\begin{array}{c}\text { Water } \\
\text { Cloud/Stratocumulus/ } \\
\text { Stratus }\end{array}$ & $\mathrm{D}$ & $\mathrm{D}$ & $\mathrm{D}$ & $\mathrm{D}$ & $\mathrm{D}$ & $\mathrm{D}$ & $\mathrm{D}$ & $\mathrm{D}$ & $\mathrm{D}$ & $\mathrm{D}$ & $\mathrm{D}$ & $\mathrm{D}$ \\
\hline 7 & Thick Cirrus & ND & ND & $\mathrm{D}$ & ND & $\mathrm{D}$ & ND & ND & ND & $\mathrm{D}$ & ND & $\mathrm{D}$ & ND \\
\hline 8 & Cirrus & $\mathrm{D}$ & ND & ND & ND & ND & ND & $\mathrm{D}$ & ND & $\mathrm{ND}$ & ND & ND & ND \\
\hline 9 & Thin Cirrus & $\mathrm{D}$ & ND & $\mathrm{D}$ & $\mathrm{D}$ & $\mathrm{D}$ & $\mathrm{D}$ & $\mathrm{D}$ & ND & $\mathrm{D}$ & $\mathrm{D}$ & $\mathrm{D}$ & $\mathrm{D}$ \\
\hline & Surface temperature & \multicolumn{2}{|c|}{$T \mathrm{~s}=288 \mathrm{~K}$} & \multicolumn{2}{|c|}{$T \mathrm{~s}=286 \mathrm{~K}$} & \multicolumn{2}{|c|}{$T s=288 \mathrm{~K}$} & \multicolumn{2}{|c|}{$T \mathrm{~s}=295 \mathrm{~K}$} & \multicolumn{2}{|c|}{$T \mathrm{~s}=299 \mathrm{~K}$} & \multicolumn{2}{|c|}{$T \mathrm{~s}=301 \mathrm{~K}$} \\
\hline & $\begin{array}{l}\text { Cloud top temperature } \\
\text { timated cloud top height }\end{array}$ & \multicolumn{2}{|c|}{$\begin{array}{c}T_{\mathrm{CT}}=288 \mathrm{~K} \\
h=0 \mathrm{~km}\end{array}$} & \multicolumn{2}{|c|}{$\begin{array}{l}T_{\mathrm{CT}}=240 \mathrm{~K} \\
h=7.1 \mathrm{~km}\end{array}$} & \multicolumn{2}{|c|}{$\begin{array}{l}T_{\mathrm{CT}}=248 \mathrm{~K} \\
h=6.1 \mathrm{~km}\end{array}$} & \multicolumn{2}{|c|}{$\begin{array}{l}T_{\mathrm{CT}}=289 \mathrm{~K} \\
h=2.8 \mathrm{~km}\end{array}$} & \multicolumn{2}{|c|}{$\begin{array}{l}T_{\mathrm{CT}}=257 \mathrm{~K} \\
h=6.4 \mathrm{~km}\end{array}$} & \multicolumn{2}{|c|}{$\begin{array}{l}T_{\mathrm{CT}}=290 \mathrm{~K} \\
h=1.7 \mathrm{~km}\end{array}$} \\
\hline- & Classification result: & \multicolumn{2}{|c|}{ No cloud } & \multicolumn{2}{|c|}{ Dense Cirrus } & \multicolumn{2}{|c|}{ Dense Cirrus } & \multicolumn{2}{|c|}{ Thin Cirrus } & \multicolumn{2}{|c|}{ Cirrus } & \multicolumn{2}{|c|}{ Stratocumulus } \\
\hline- & Verification result: & \multicolumn{2}{|c|}{$=$ True } & \multicolumn{2}{|c|}{$=$ True } & \multicolumn{2}{|c|}{$=$ True } & \multicolumn{2}{|c|}{$=$ False } & \multicolumn{2}{|c|}{$=$ True } & \multicolumn{2}{|c|}{$=$ True } \\
\hline
\end{tabular}

Note: $\mathrm{D}=$ Detected; $\mathrm{ND}=$ Not detected; SWA = Split Window Algorithm. 
detected as water cloud because of the similarity in albedo values. Usually such situations occur during winter season in the northern area of Japan. Practically speaking, however, the snow areas can easily be delineated using the image movie of Himawari-8. The other difficulty encountered in the present SWA is the precise detection of very thin cirrus clouds, which are mostly detected as clear area.

The verification of cloud classification results is implemented using the CALIPSO data. Figure 6(a) shows an example, where the CALIPSO flight track is superposed on the map of cloud classification based on SWA13-15 for the case of 03:40 UTC on July 2, 2016. Two ranges (A and B) are defined along the flight track to examine the temporal change of parameters, namely, the depolarization ratio $(\rho)$, ice/water phase, and the cloud type. The time-height indicator (THI) representation of the depolarization ratio is shown in Figure 6(b), while that of the ice/water phase in Figure 6(c), both of which have been downloaded from

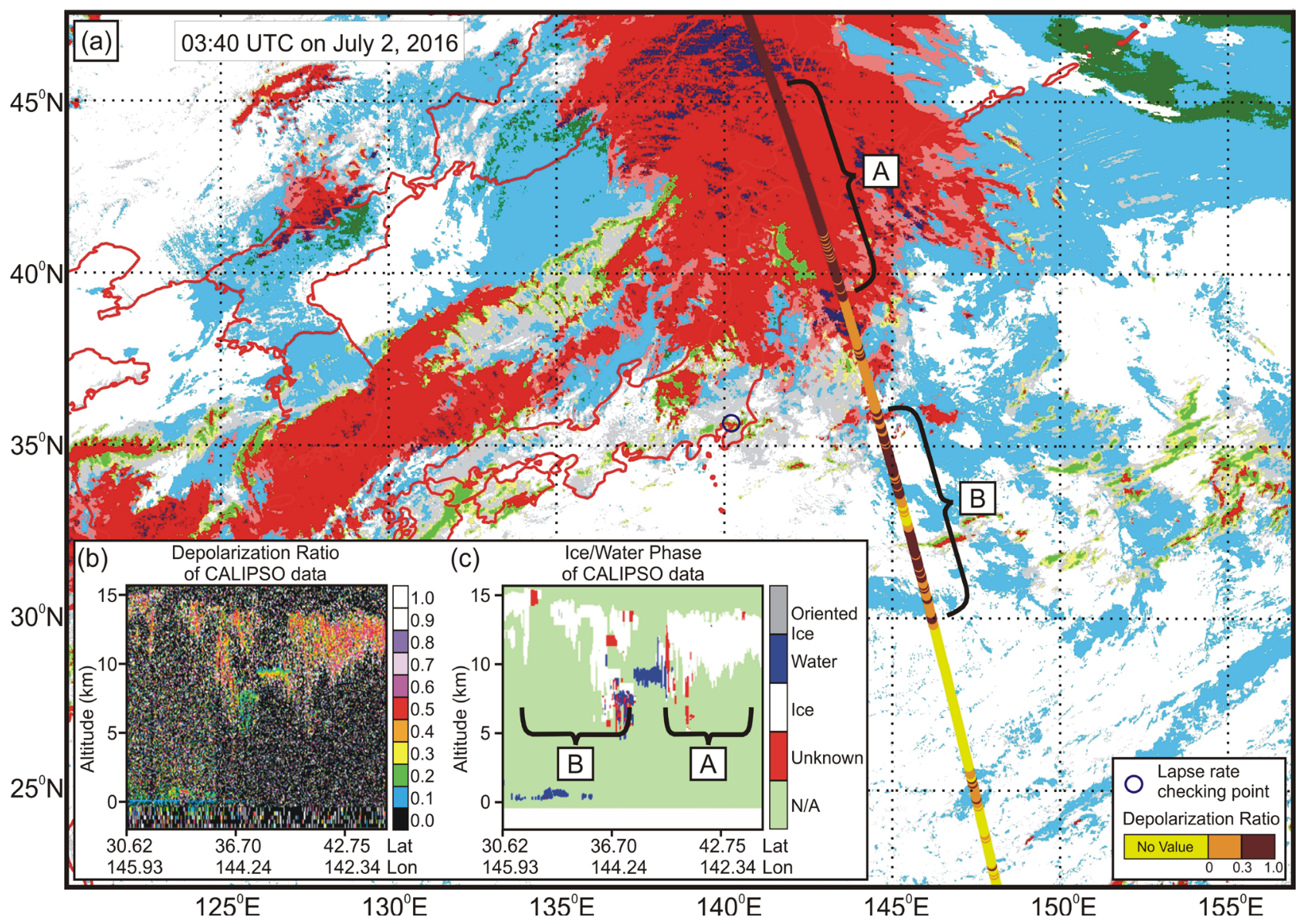

Figure 6. Verification of the cloud classification results based on SWA13-15 against the concurrent CALIPSO data. (a) Enlarged map of dataset \#5 (July 2, 2016) superposed with the CALIPSO track, with indication of the range of depolarization value $(\rho$ ). Track color of dark brown shows the range of $\rho>0.3$, indicating the occurrence of ice clouds. The blue circle is the location of Chiba, where the altitude verification was made by considering lapse rate; (b) Time-height indicator (THI) representation of the depolarization ratio of CALIPSO data. The relevant (Japan) area was cropped from the original data. Red color indicates the presence of ice clouds; (c) THI representation of the cloud phases that shows the dominance of ice particle (white color) at higher altitudes. 
the CALIPSO website. The level of depolarization ratio is indicated in the track using different colors showing no value (yellow), $\rho<0.3$ (brown), and $\rho>0.3$ (dark brown). This last category stands for ice cloud, which corresponds to dense cirrus (type \#4, red) or cumulonimbus (type \#1, blue). Thus, the present result of cloud classification around region A (dense cirrus) can be confirmed using the large $\rho$ value from the concurrent CALIPSO data. In region B, on the other hand, the $\rho$ value is larger than 0.3 , but the classification result suggests clear area. More close examination of the image movie, however, indicates that the actually, the region is covered with very thin cirrus. Thus, this discrepancy is ascribable to the difficulty in detecting very thin cirrus clouds by using the SWA based on BT and BTD. Figure 6(c) shows the THI representation of the cloud phases. The dominance of ice particles (white color) is consistent with the presence of high-level clouds such as dense cirrus or cumulonimbus. Similar validation using the concurrent CALIPSO data has led to the conclusion that the classification based on both SWA is acceptable.

The altitude verification is performed at Chiba, indicated with a blue circle in Figure 5(a). The value of surface temperature, $T_{\mathrm{S}}$, is derived from the ground observation at Chiba University, while that of cloud top, $T_{\mathrm{CT}}$, from the BT of the corresponding pixel of Himawari-8. The results of altitude verification are summarized at the bottom of Table 4. For dataset \#1, the estimated cloud top height, $h$, is $0 \mathrm{~km}$, which agrees with the classification result of clear (no cloud) area. For dataset \#2, the resulting value of $h=7.1 \mathrm{~km}$ is reasonable for the cloud type of dense cirrus. Similarly, good agreements have been found for other datasets except dataset \#4. The resulting value of $h=2.8 \mathrm{~km}$ is inconsistent with the classification result thin cirrus, a type of high clouds. Thin cirrus clouds exhibit the value of $T_{\mathrm{CT}}$ that is close to the surface temperature, $T_{\mathrm{S}}$, because of their semi-transparent features.

The comparation of SWA13-15 and SWA15-16 has indicated that generally the first combination can exhibit more sensitivity for different cloud types than the latter, as manifested in the wider spread in the scatter plot diagrams (Figure 4). However the latter combination of SWA tends to discriminate rain cloud regions among cumulonimbus and dense cirrus clouds. Nevertheless, the results from both SWAs are not contradictory to each other, as verificated by using the CALIPSO depolarisation ratio data.

\section{Conclusion}

This paper has described the effectiveness of SWA for detecting the cloud types using the IR bands of Himawari-8 satellite. Verification has been made with the space-borne lidar (CALIPSO) data and lapse rate consideration. Through the implementation of SWA, the following nine types of clouds have been successfully distinguished around the Japan area: high cumulonimbus, middle cumulonimbus, cumulus, dense cirrus, ice cloud, water cloud, thick cirrus, cirrus, and thin cirrus as summarized in the form of a SWA matrix. The classification re- 
sults have been compared for the two cases of SWA, namely, SWA13-15 and SWA15-16. Scatter plot diagrams between BT and BTD are examined for both SWA, showing that generally more cloud types are detected with SWA13-15 $(10.4$ vs. $12.4 \mu \mathrm{m})$ as compared with SWA15-16 (12.4 vs. $13.3 \mu \mathrm{m})$. This is ascribed to the fact that the SWA13-15 diagram tends to spread more widely than SWA15-16 diagram in both winter and summer seasons. The latter SWA, however, is found to be more effective in detecting the region of cumulonimbus (i.e. likely rainfall region) amidst that of dense cirrus. In accordance with the variation in climate conditions, different values of BT and BTD thresholds have been determined from the close examination of cloud types. It is difficult to detect thin cirrus and very thin cirrus clouds using BT and BTD because of their semi-transparency. The coupled information on BT and surface temperature, however, is useful for solving this problem, leading to better discrimination between thin cirrus and clear regions. Combining the ancillary data from either space-borne or ground-based lidar will also be useful in this context. Finally, it is emphasized that the use of high frequency data of Himawari- 8 is available every 10 min at full disk and 2.5 min around Japan, as an image movie makes it possible to detect detailed movement in cloud systems. Snow-covered areas, which tend to be classified as water cloud or cirrus cloud, can easily be delineated in such a movie type examination.

\section{Acknowledgements}

One of the authors (B.P.) expresses his gratitude to the financial supports, Ministry of Research, Technology and Higher Education (RISTEKDIKTI), Republic of Indonesia through the Scholarship Program for Research and Innovation in Science and Technology (RISET-Pro).

\section{Conflicts of Interest}

The authors declare no conflicts of interest regarding the publication of this paper.

\section{References}

[1] Bessho, K., Date, K., Hayashi, M., Ikeda, A., Imai, T., Inoue, H., Kumagai, Y., Miyakawa, T., Murata, H., Ohno, T., Okuyama, A., Oyama, R., Sasaki, Y., Shimazu, Y., Shimoji, K., Sumida, Y., Suzuki, M., Taniguchi, H., Tsuchiyama, H., Uesawa, D., Yokota, H. and Yoshida, R. (2016) An Introduction to Himawari-8/9-Japan's New-Generation Geostationary Meteorological Satellites. Journal of the Meteorological Society of Japan, 94, 151-183. https://doi.org/10.2151/jmsj.2016-009

[2] Ackerman, S.A., Strabala, K.I., Menzel, W.P., Frey, R.A., Moeller, C.C. and Gumley, L.E. (1998) Discriminating Clear Sky from Clouds with MODIS. Journal of Geophysical Research, 103, 32141-32157. https://doi.org/10.1029/1998JD200032

[3] Remer, L.A., Kaufman, Y.J., Tanré, D., Mattoo, S., Chu, D.A., Martins, J.V., Li, R.R., Ichoku, C., Levy, R.C., Kleidman, R.G., Eck, T.F., Vermote, E. and Holben, B.N. (2005) The MODIS Aerosol Algorithm, Products, and Validation. Journal of the Atmospheric Sciences, 62, 947-973. https://doi.org/10.1175/JAS3385.1 
[4] Gao, B., Meyer, K. and Yang, P. (2004) A New Concept on Remote Sensing of Cirrus Optical Depth and Effective Ice Particle Size Using Strong Water Vapor Absorption Channels Near 1.38 and $1.88 \mu \mathrm{m}$. IEEE Transactions on Geoscience and Remote Sensing, 42, 1891-1899. https://doi.org/10.1109/TGRS.2004.833778

[5] Lutz, H.J., Inoue, T. and Schmetz, J. (2003) Comparison of a Split-Window and a Multi-Spectral Cloud Classification for MODIS Observations. Journal of the Meteorological Society of Japan, 81, 623-631. https://doi.org/10.2151/jmsj.81.623

[6] Santurette, P. and Georgiev, C.G. (2007) Water Vapour Imagery Analysis in $7.3 \mu / 6.2 \mu$ for Diagnosing Thermo-Dynamic Context of Intense Convection. Proceedings of Joint 2007 EUMETSAT Meteorological Satellite Conference and the 15th AMS Satellite Meteorology \& Oceanography Conference, Amsterdam, 24-28 September 2007, 24-28.

[7] Krebs, W., Mannstein, H., Bugliaro, L. and Mayer, B. (2007) A New Day- and Night-Time Meteosat Second Generation Cirrus Detection Algorithm MeCidA. Atmospheric Chemistry and Physics, 7, 6145-6159. https://doi.org/10.5194/acp-7-6145-2007

[8] Thies, B., Nauß, T. and Bendix, J. (2008) Discriminating Raining from Non-Raining Cloud Areas at Mid-Latitudes Using Meteosat Second Generation SEVIRI Night-Time Data. Meteorological Applications, 15, 219-230.

https://doi.org/10.1002/met.56

[9] Nacario, R.G., Perez, G.J. and Bagtasa, G. (2016) Rainfall Detection Using the Infrared Bands of Himawari-8 Advanced Himawari Imager in the Philippines. Proceedings of Asian Conference on Remote Sensing, Colombo, 17-21 October 2016.

[10] Strabala, K.I., Ackerman, S.A. and Menzel, W.P. (1994) Cloud Properties Inferred from 8 - 12- $\mu \mathrm{m}$ data. Journal of Applied Meteorology, 33, 212-229. https://doi.org/10.1175/1520-0450(1994)033<0212:CPIFD>2.0.CO;2

[11] Mouri, K., Izumi, T., Suzue, H. and Yoshida, R. (2016) Algorithm Theoretical Basis Document of Cloud Type/Phase Product. Meteorological Satellite Center Technical Note, 61, 19-31.

[12] Shang, H., Chen, L., Letu, H., Zhao, M., Li, S. and Bao, S. (2017) Development of a Daytime Cloud and Haze Detection Algorithm for Himawari-8 Satellite Measurements over Central and Eastern China. Journal of Geophysical Research: Atmospheres, 122, 3528-3543. https://doi.org/10.1002/2016JD025659

[13] Rozenstein, O., Qin, Z., Derimian, Y. and Karnieli, A., (2014) Derivation of Land Surface Temperature for Landsat-8 TIRS Using a Split Window Algorithm. Sensors, 14, 5768-5780. https://doi.org/10.3390/s140405768

[14] Yu, X., Guo, X. and Wu, Z. (2014) Land Surface Temperature Retrieval from Landsat 8 TIRS-Comparison between Radiative Transfer Equation-Based Method, Split Window Algorithm and Single Channel Method. Remote Sensing, 6, 9829-9852. https://doi.org/10.3390/rs6109829

[15] Hulley, G.C., Hook, S.J. and Schneider, P. (2011) Optimized Split-Window Coefficients for Deriving Surface Temperatures from Inland Water Bodies. Remote Sensing of Environment, 115, 3758-3769. https://doi.org/10.1016/j.rse.2011.09.014

[16] Quan, W., Chen, H., Han, X., Liu, Y. and Ye, C. (2012) A Modified Becker's Split-Window Approach for Retrieving Land Surface Temperature from AVHRR and VIRR. Acta Meteorologica Sinica, 26, 229-240. https://doi.org/10.1007/s13351-012-0208-y

[17] Jiang, G.M., Zhou, W. and Liu, R. (2013) Development of Split-Window Algorithm for Land Surface Temperature Estimation from the VIRR/FY-3A Measurements. 
IEEE Geoscience and Remote Sensing Letters, 10, 952-956. https://doi.org/10.1109/LGRS.2013.2255859

[18] Nishi, N., Hamada, A. and Hirose, H. (2017) Improvement of Cirrus Cloud-Top Height Estimation Using Geostationary Satellite Split-Window Measurements Trained with CALIPSO Data. SOLA, 13, 240-245. https://doi.org/10.2151/sola.2017-044

[19] Inoue, T. (1987) A Cloud Type Classification with NOAA 7 Split-Window Measurements. Journal of Geophysical Research: Atmospheres, 92, 3991-4000. https://doi.org/10.1029/JD092iD04p03991

[20] Hamada, A., Nishi, N., Kida, H., Shiotani, M., Iwasaki, S., Kamei, A., Ohno, Y., Kuroiwa, H., Kumagai, H. and Okamoto, H. (2004) Cloud Type Classification by GMS-5 Infrared Split-Window Measurements with Millimeter-Wave Radar and TRMM Observations in the Tropics. 2nd TRMM International Science Conference, Nara, 6-10 September 2004.

[21] Inoue, T. and Ackerman, S.A. (2002) Radiative Effects of Various Cloud Types as Classified by the Split Window Technique over the Eastern Sub-Tropical Pacific Derived from Collocated ERBE and AVHRR Data. Journal of the Meteorological Society of Japan, 80, 1383-1394. https://doi.org/10.2151/jmsj.80.1383

[22] Vaughan, M.A., Powell, K.A., Winker, D.M., Hostetler, C.A., Kuehn, R.E., Hunt, W.H., Getzewich, B.J., Young, S.A., Liu, Z. and McGill, M.J. (2009) Fully Automated Detection of Cloud and Aerosol Layers in the CALIPSO Lidar Measurements. Journal of Atmospheric and Oceanic Technology, 26, 2034-2050. https://doi.org/10.1175/2009JTECHA1228.1

[23] Aguado, E. and Burt, J.E. (2013) Understanding Weather and Climate. 6th Edition, Pearson Education, London.

[24] Japan Meteorological Agency (2015) Himawari-8/9 Standard Data User's Guide. https://www.data.jma.go.jp/mscweb/en/himawari89/space_segment/hsd_sample/H S_D_users_guide_en_v12.pdf

[25] Beesley, J.A., Bretherton, C.S., Jakob, C., Andreas, E.L., Intrieri, J.M. and Uttal, T.A. (2000) A Comparison of Cloud and Boundary Layer Variables in the ECMWF Forecast Model with Observations at Surface Heat Budget of the Arctic Ocean (SHEBA) Ice Camp. Journal of Geophysical Research: Atmospheres, 105, 12337-12349. https://doi.org/10.1029/2000JD900079

[26] Zhang, W., Wei, M., Yu, T., Wang, G., Lai, J. and Wang, Y. (2010) Study in Retrieval Visibility and Optical Thickness of Fog with MODTRAN. International Conference on Multimedia Technology (ICMT), Ningbo, 29-31 October 2010.

[27] Ahrens, C.D. (2009) Meteorology Today: An Introduction to Weather, Climate, and the Environment. 9th Edition, Cengage Learning, Boston. 